\title{
Cleanliness of Mixed Fired Clay Bricks Coming from Construction and Demolition Waste
}

\author{
E. Cilli ${ }^{1} \cdot$ M. A. Bruneaux ${ }^{2} \cdot$ L. Chateau ${ }^{3} \cdot$ J. M. Lucatelli ${ }^{4}$. \\ C. Peyratout ${ }^{1} \cdot$ A. Smith ${ }^{1}$
}

Received: 18 July 2016/Accepted: 7 November 2016/Published online: 24 November 2016

(c) The Author(s) 2016. This article is published with open access at Springerlink.com

\begin{abstract}
Recycling of construction and demolition waste containing mixtures of fired clay and gypsum implies a separation process which aims to obtain individual fired clay and gypsum aggregates. This paper presents a method to quantify very small amounts of gypsum that still adhere at the fired clay bricks surface after the separation process. This may require a single or several steps. Leaching studies were carried out on mixed fired clay bricks and gypsum powder, by measuring the electrical conductivity of the water. Results show that maximum electrical conductivity of mixed fired clay and gypsum powder in contact with water can be correlated to gypsum content present in corresponding mixture. Therefore, electrical conductivity could be a method to evaluate the amount of gypsum which still remains at the surface of fired clay bricks after separation.
\end{abstract}

Keywords Fired clay bricks · Gypsum · Demolition waste $\cdot$ Leaching tests Electrical conductivity

\footnotetext{
A. Smith

agnes.smith@unilim.fr

1 Laboratoire Science des Procédés Céramiques et de Traitements de Surface, UMR CNRS, 7315 Limoges, France

2 Centre Technique de Matériaux Naturels de Construction, Clamart, France

3 Agence de l'Environnement et de la Maîtrise de l'Energie, Angers, France

4 Veolia Recherche et Innovation, Limay, France
}

\section{Introduction}

The construction and demolition industries generate in European Union around 900 million tons of waste per year [1]. Inert waste represents between 40 and $85 \%$ of the overall waste volume discounting excavation soils from this waste [2]. Construction and demolition waste (C\&DW) is produced mainly during building rehabilitation and demolition phases [3]. Recovery of C\&DW from private or industrial buildings based on heavy clay products concern covering elements and masonry elements. Covering elements, such as roof tiles, are mechanically assembled and therefore easily recovered and reused, whereas masonry elements are an assembly of fired clay bricks, mortar for seals and gypsum, bonded to each other and therefore difficult to recycle. European Decision 2003/33/EC, regarding landfilling of waste, considers waste as inert "if it does not undergo any significant physical, chemical or biological transformations. Inert waste will not dissolve, burn or otherwise physically or chemically react, biodegrade or adversely affect other matter with which it comes into contact in a way likely to give rise to environmental pollution or harm human health. The total leachability and pollutant content of the waste must be insignificant and in particular not endanger the quality of surface water and/or groundwater." According to this decree, composite waste cannot be considered as inert waste, especially because of gypsum. According to European Decision 2003/33/EC, the maximum acceptable concentration of sulphates in water is $2000 \mathrm{mg} / \mathrm{L}$ (for a liquid-to-solid ratio of $10 \mathrm{~L} / \mathrm{kg}$ ). However, water solubility of gypsum is $2100 \mathrm{mg} / \mathrm{L}$ at $25^{\circ} \mathrm{C}$. Therefore, gypsum is likely to release higher-than-permitted levels of sulphate ions and pollute water sources [4]. Under anaerobic conditions, that can occur when the gypsum containing materials are used as underground 
construction materials or deposited in landfilled sites, toxic $\mathrm{H}_{2} \mathrm{~S}$ gas can be generated because of the reaction between soluble sulphates and organic matter [5]. Available scientific papers show the current restrictions to recycle waste containing gypsum. For example, incorporation of gypsum waste in mortar blocks has led to lower mechanical properties than reference mortars and consequently to shorter durability of the recycled mortar [6, 7]. Gypsum has a negative impact on the recycled mortar or concrete properties because of its low hardness and low density. Moreover, water soluble sulphates sourced from gypsum are likely to react with cement and may give rise to expansive reactions [8]. Recovery of mixed C\&DW from roadworks is also regulated, particularly regarding sulphate leachability of aggregates [9]. According to a study conducted by Vegas et al. [10], aggregates used for roadworks should not contain more than $0.8 \%$ by weight of gypsum. The UNEEN 13139: 2002 standard "aggregates for mortar" established a limit of $1 \%$ by weight for the total sulfur content for aggregates used in mortar preparation [11].

Nowadays, there are 3 classes of landfill plants: inert waste are landfilled in sites of class 3, class 2 concerns non inert but non dangerous waste and finally, class 1 is reserved for hazardous waste. Currently, the main end-oflife option for non-dissociated waste of fired clay, gypsum and mortar from demolition is the landfilling in landfill plants of class 2 .

Prior to recycling and valorizing fired clay based demolition waste, a two step process is necessary: (1) separation of materials, especially fired clay and gypsum, (2) use $a s$-is or transformation of these separated materials for use as secondary raw materials in other industrial sectors. After the first step, it is necessary to make sure that the individual separated materials can be re-used in one of the identified routes for recycling/recovery. Monitoring the efficiency of the separation method is an important step; indeed, the degree of cleanliness of fired clay bricks and gypsum obtained after the separation step directs these secondary raw materials towards preferred applications. Controlling the separation efficiency implies quantification of the amount of gypsum that still adheres to fired clay after the separation process and also guarantees the quality of the secondary raw material. The controlling technique has to give precise, fast and repeatable measurements. Different studies were conducted to evaluate demolition waste behaviour when there is contact with water, for fired clay bricks, gypsum and mortar. These revealed that the leachate compositions are different depending on the proportions and nature of materials [12]. High leaching of sulphate ions was measured for masonry-containing samples; it is the opposite for fired clay samples. Furthermore, leaching tests are a quantitative means for determining whether C\&DW can be regarded as inert waste [13]. The focus of the present work is to correlate the sulphate leachability to gypsum content and therefore determine if fired clay bricks still contain very small amounts of gypsum. The monitoring of sulphate leachability is carried out by electrical conductivity measurements as a function of time.

\section{Materials and Methods}

\section{Materials}

For this study, two kinds of aggregates were studied. They came from two different C\&DW processing plants, one located in the East (E) of France and the other in the SouthWest (SW) of France. These aggregates were mixed waste of fired clay bricks and gypsum meaning that fired clay brick and gypsum stick together. Two kinds of fired clay bricks were considered: facing bricks $(\mathrm{FB})$ and perforated bricks (HB).

\section{Sample Preparation}

Mixed aggregates were sampled from the SW and E waste sorting plants. Laboratory samples were obtained by representative mass quartering of the primary samples and then by riffle splitting. Studies were also carried out on single fired clay bricks and gypsum samples, and on reconstituted mixtures prepared in the laboratory by mixing known percentages of gypsum with fired clay bricks. For this purpose, single fired clay bricks and gypsum samples were crushed to $125 \mu \mathrm{m}$ and then mixed with appropriate mass contents. The nomenclature used to describe the studied single samples of fired clay bricks and reconstituted samples are respectively: A_B and A_B_x_G_y where A designates the origin of the waste (E for East and $\mathrm{SW}$ for South West), B the type of brick (HB for clay hollow brick and FB for clay facing brick), $G$ for gypsum and $x$ and $y$ are respectively percentages by weight of fired clay brick and gypsum in the blends. All tests were performed with crushed materials sieved to $125 \mu \mathrm{m}$. The samples were then dried in an oven at $60{ }^{\circ} \mathrm{C}$ until the mass was constant.

\section{Sample Composition}

Elemental composition of single materials, i.e. fired clay bricks and gypsum, was determined by ICP-AES after microwave assisted digestion in $\mathrm{HF} / \mathrm{HNO}_{3} / \mathrm{HCl}$. Samples were previously ground to obtain a particle size smaller than $63 \mu \mathrm{m}$. The equipment used was an ICP AES 8300 DV (Perkin Elmer) consisting of an optical spectrometer with a dual sighting (radial sighting and axial sighting). $\mathrm{X}$-ray diffraction (XRD) analysis was carried out on 
powdered samples to characterize the structure of the materials, using a Bruker-AXS D5000 diffractometer with $\mathrm{CuK} \alpha$ radiation and a graphite back-monochromator. XRD experiments were made in the step-scan mode from $10^{\circ}$ to $70^{\circ}$ with a counting time of $10.1 \mathrm{~s}$ per $0.02^{\circ}$ step. Crystalline phases were identified by comparison with PDF standards (Powder Diffraction Files) from ICDD (the International Center for Diffraction Data).

\section{Leaching Experiments}

Leaching experiments were conducted to follow the behaviour of demolition waste in contact with water over time. When exposed to water, soluble ions migrate from the solid materials towards the enveloping solution. Ion concentrations are then modified and create a variation of the solution electrical conductivity, which is directly proportional to the nature and the concentration of ions in the solution. It can be expressed according Kohlrausch's law (Eq. 1):

$\sigma=\sum_{\mathrm{i}} \lambda_{\mathrm{i}} \mathrm{z}_{\mathrm{i}} \mathrm{C}_{\mathrm{i}}$

where $\sigma=$ total electrical conductivity $\left(\mathrm{S} \cdot \mathrm{cm}^{-1}\right) \lambda_{\mathrm{i}}=$ mobility of compound $i$ at chosen temperature $\left(S \cdot \mathrm{cm}^{2}\right.$. $\left.\mathrm{mol}^{-1}\right) \mathrm{z}_{\mathrm{i}}=$ electrical charge of compound $\mathrm{i} \mathrm{C}_{\mathrm{i}}=$ concentration of compound $\mathrm{i}$ in the solution $\left(\mathrm{mol} \mathrm{cm}{ }^{-3}\right)$.

These measurements were carried out using an electrical conductimeter. Deionized water was chosen as a leaching fluid because its electrical conductivity is nearly $0 \mathrm{~S} \cdot \mathrm{cm}^{-1}$. Tap water was avoided because the ion content depends on the geographical location; it could affect the electrical conductivity measurements. Electrical conductivity was studied using a multiplexer set (Multicad 4 from CAD Instruments). Samples were subjected to a leaching test based on a liquid-to-solid ratio of $10 \mathrm{~L} \mathrm{~kg}^{-1}$. Measuring cells are stirred throughout the duration of the test. After stabilization of the electrical conductivity values, the suspensions were filtered ( $3 \mu \mathrm{m}$ filter).

\section{Leaching Characterization}

Leachate solutions were analyzed by ICP-AES to measure the amount of ions mobilized when the powders were in contact with water, and ion chromatography analysis was specifically carried out to measure the sulphate concentration in the leachates. The equipment used is a chromatograph ICS 2500 of Thermo Fisher-Dionex with an anion column. The tests were performed in accordance with the standard NF EN ISO 10304-1 for the determination of dissolved anion amounts by liquid chromatography [14].

\section{Results and Discussion}

\section{Elemental Analysis and X-ray Diffraction of Fired Clay Bricks and Gypsum}

The elemental compositions of single fired clay bricks (hollow brick and facing brick) and gypsum samples were determined by ICP-AES and are given in Table 1 .

Fired clay bricks samples are made up mainly of alumina $\left(\mathrm{Al}_{2} \mathrm{O}_{3}\right)$ and silica $\left(\mathrm{SiO}_{2}\right)$. The other oxides are present in low quantities. In the case of gypsum, sulfur, which is present in the form of sulphate $\left(\mathrm{SO}_{4}{ }^{2-}\right)$, is the main constituent with calcium. Sulfur which is also a constituent of fired clay bricks is likely to be leached out in the form of sulphate when exposed to water. Silica is also present. The very high silica content could be due to mineral additives mixed with calcium sulfate hemihydrates during production of gypsum. However, since the studied C\&DW came from old buildings constructed at a time when traceability did not exist, it is difficult to identify the exact origin of the silica.

Single fired clay bricks samples E_HB, E_FB, SW_HB and SW_FB were analysed by XRD in order to identify the crystalline phases (Fig. 1).

Crystalline composition does not seem to be influenced by the nature of the fired clay bricks. Actually, all X-ray diffraction patterns are similar. These fired clay bricks contain:

- quartz and plagioclase feldspars like anorthite and albite,

- gehlenite and wollastonite due to calcite which is in the initial clay,

- diopside and hematite originating respectively from dolomite $\left(\mathrm{CaO}, \mathrm{MgO}, 2 \mathrm{CO}_{2}\right)$ and goethite $\left(\mathrm{Fe}_{2} \mathrm{O}_{3}\right.$, $\left.\mathrm{H}_{2} \mathrm{O}\right)$,
Table 1 Chemical compositions of single fired clay bricks (clay hollow brick and clay facing brick) and gypsum samples

\begin{tabular}{lcccccccccc}
\hline By weight (\%) & $\mathrm{SiO}_{2}$ & $\mathrm{Al}_{2} \mathrm{O}_{3}$ & $\mathrm{Fe}_{2} \mathrm{O}_{3}$ & $\mathrm{CaO}$ & $\mathrm{K}_{2} \mathrm{O}$ & $\mathrm{MgO}$ & $\mathrm{Na}_{2} \mathrm{O}$ & $\mathrm{TiO}_{2}$ & $\mathrm{SO}_{3}$ & Loss on ignition \\
\hline E_HB & 68.5 & 14.6 & 5.4 & 4.3 & 2.1 & 1.8 & 0.8 & 0.9 & 0.6 & 1.0 \\
E_FB & 68.2 & 10.6 & 4.0 & 9.4 & 2.2 & 2.1 & 1.1 & 0.7 & 0.6 & 1.1 \\
SW_HB & 69.6 & 12.3 & 3.9 & 4.2 & 3.1 & 1.6 & 0.7 & 0.5 & 0.9 & 3.2 \\
SW_FB & 68.3 & 15.5 & 5.6 & 2.0 & 2.8 & 1.8 & 1.1 & 0.8 & 0.1 & 2.0 \\
Gypsum & 18.8 & 3.5 & 0.9 & 26.7 & 1.2 & 2.2 & 0.3 & 0.3 & 28.7 & 17.4 \\
\hline
\end{tabular}




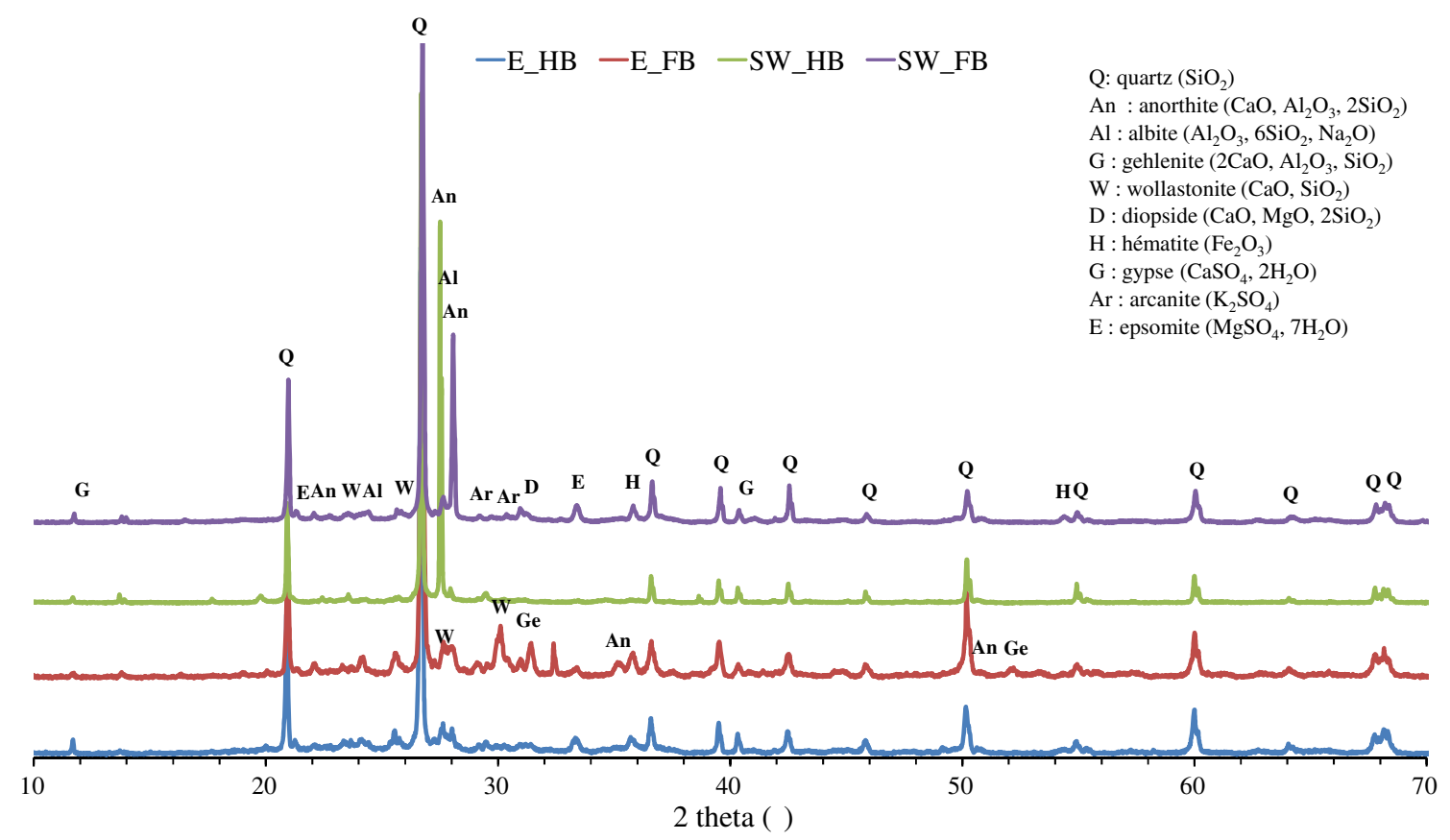

Fig. 1 Diffractograms of E_HB, E_FB, SW_HB and SW_FB samples

Table 2 Water solubilities at $20{ }^{\circ} \mathrm{C}$ and melting temperatures of some sulphated compounds [15]

\begin{tabular}{lcl}
\hline & $\begin{array}{l}\text { Water } \\
\text { solubility }(\mathrm{g} / \mathrm{L})\end{array}$ & $\begin{array}{l}\text { Melting } \\
\text { temperature }\left({ }^{\circ} \mathrm{C}\right)\end{array}$ \\
\hline Calcium sulphate & 2 & 1460 \\
Potassium sulphate & 110 & 1069 \\
Magnesium sulphate & 270 & 1124 \\
\hline
\end{tabular}

- sulphated compounds such as gypsum, arcanite and epsomite.

The sources of these sulphates present in fired clay bricks are various. They could either be contained in the initial raw mix and not be decomposed during firing, or brought by the mixing water used for the hydraulic binder. Table 2 lists water solubilities and melting temperatures of sulphated compounds identified in the diffractograms of the studied fired clay bricks [15].

Table 2 shows that all these sulphated compounds have a melting temperature higher than $1000{ }^{\circ} \mathrm{C}$. However, clay bricks are usually fired at around $1000{ }^{\circ} \mathrm{C}$. Therefore, sulphated compounds identified by XRD are likely to originate from the fired clay bricks. Since sulphated compounds are soluble in water, their presence in fired clay bricks can be detrimental. Actually, they can cause efflorescence, which is salt exudation due to migration of salinated water from the bulk to the external surface of porous material over time. It can reduce adhesion of mortar and coatings to fired clay bricks. It is a disadvantage since the leaching of these ions, in very high quantities, would be a major impediment to the recovery of fired clay bricks as secondary raw materials in other industrial sectors [15]. Barbudo et al. [7] showed that the sulphates in leaching processes came not only from gypsum, but the fired clay materials exhibited also soluble sulphates.

\section{Conductivity of Individual Fired Clay Bricks and Gypsum Samples}

Leaching tests by electrical conductivity measurements were conducted in order to evaluate the behavior of fired clay bricks and gypsum when they are exposed to water (Fig. 2). Thus, electrical conductivity of fired clay bricks, mortar and gypsum were each measured over time. Electrical conductivity of a solution is proportional to its ion concentration.

In Fig. 2, the curves are similar whatever the nature of fired clay bricks. The electrical conductivity increases gradually to reach a plateau.

For fired clay bricks (FB or HB), electrical conductivity always increases towards a maximum asymptotic value. Maximum conductivity obtained for fired clay bricks originating from the South-West (SW_HB, SW_FB) is 


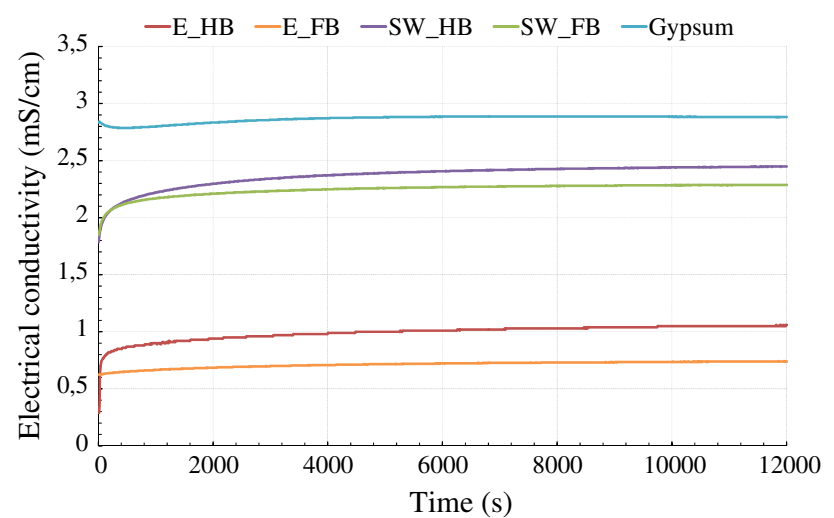

Fig. 2 Electrical conductivity of single fired clay bricks and gypsum samples as a function of time

higher than for fired clay bricks coming from the East (E_HB, E_FB). Moreover, for a given geographical location, clay hollow bricks (HB) have a greater value of electrical conductivity than clay facing bricks (FB).

Gypsum behaves differently when it is in contact with water. The gypsum sample presents the highest electrical conductivity value at the beginning of the experiment. Over time, its conductivity slightly decreases and increases again to reach a plateau. The decrease is due to the initial sulphate concentration in the solution that is higher than the water solubility of calcium sulphate, causing over-saturation of the solution and therefore re-precipitation of calcium sulphates.

Once the electrical conductivity was stabilized, solutions were filtered. Maximum achievable cation contents of the leachates were determined by ICP-AES and by ion chromatography to measure sulphate $\left(\mathrm{SO}_{4}{ }^{2-}\right)$ concentrations (Table 3).

Calcium $\left(\mathrm{Ca}^{2+}\right)$ and sulphate $\left(\mathrm{SO}_{4}{ }^{2-}\right)$ ions were released from fired clay bricks in very high quantities compared to other ions. Released sulphates can originate either from calcium sulphate, magnesium sulphate or potassium sulphate which were identified by XRD. Calcium and sulphate concentrations evolve in the same way as electrical conductivity. Actually, calcium and sulphate

Table 3 Maximum achievable ion contents (in $\mathrm{mg} / \mathrm{L}$ ) of the fired clay bricks and gypsum leachates

\begin{tabular}{lrrrrrrr}
\hline Sample & $\mathrm{Ca}^{2+}$ & $\mathrm{SO}_{4}{ }^{2-}$ & $\mathrm{Na}^{+}$ & $\mathrm{K}^{+}$ & $\mathrm{Mg}^{2+}$ & $\mathrm{Si}^{4+}$ & $\mathrm{Al}^{3+}$ \\
\hline E_HB & 242 & 174 & 15 & 13 & 8 & 38 & 2 \\
E_FB & 183 & 126 & 18 & 20 & 4 & 32 & 2 \\
SW_HB & 672 & 357 & 19 & 22 & 28 & 15 & 2 \\
SW_FB & 489 & 254 & 25 & 20 & 88 & 0 & 3 \\
Gypsum & 1027 & 2533 & 3 & 7 & 2 & 0 & 5 \\
\hline
\end{tabular}

concentrations values of hollow clay bricks leachates are higher than those of facing clay bricks leachates, whatever the geographical origin is. For a given type of fired clay bricks, these concentration values are higher in the case of waste coming from the South-West than from the East of France.

From ion contents of fired clay bricks and gypsum leachates, theoretical conductivities of these samples were calculated with Kohlrausch's law (Eq. 1). Calculated values are summarized in Table 4.

For fired clay brick samples, maximum calculated electrical conductivity is almost equal to experimentally obtained values. Nevertheless, it is not the case for gypsum. Calculated electrical conductivity for gypsum is much higher than experimental results. Actually, these results show that leachate from the gypsum test contains dissolved sulphate ions $\left(\mathrm{SO}_{4}{ }^{2-}\right)$ but also precipitates of calcium sulphate due to over-saturation with respect to gypsum precipitation in water.

Sulfate concentrations presented in Tables 3 and 6 were measured by ion chromatography. This technique implies the use of a highly alkaline environment $(\mathrm{NaOH})$ for dissolving all the solid phases. If gypsum $\left(\mathrm{CaSO}_{4} \cdot 2 \mathrm{H}_{2} \mathrm{O}\right)$ precipitates (even with a very small particle size) were present in the starting solution due to an over-saturation mechanism, the sodium hydroxide solution dissolves these precipitates. The sulfate concentration then becomes very high. This explains the difference between the theoretical $(7.33 \mathrm{mS} / \mathrm{cm})$ and experimental $(2.9 \mathrm{mS} / \mathrm{cm})$ electrical conductivity values for leachates obtained from the gypsum sample.

Furthermore, Amathieu et al. [16] studied the time required for the germination/growth of gypsum crystals in more and more supersaturated solutions. The supersaturation coefficient $\beta$, at $25^{\circ} \mathrm{C}$, was calculated as follows (Eq. 2):

$\beta=\frac{\mathrm{K}_{\mathrm{S}}(\text { experimental })}{\mathrm{K}_{\mathrm{S}}(\text { theoretical })}$

with $\mathrm{K}_{\mathrm{S}} \quad($ experimental $)=\left[\mathrm{Ca}^{2+}\right] \cdot\left[\mathrm{SO}_{4}{ }^{2-}\right] \quad$ and $\mathrm{K}_{\mathrm{S}}$ $($ theoretical $)=2.57 \times 10^{-5}$.

Amathieu et al. showed that if $\beta \geq 4$, gypsum germination was very fast $(<1 \mathrm{~min})$. From our experimental data (Table 3), the supersaturation coefficient $\beta$ has been calculated and the results are presented in Table 5.

This table shows that the leachate from the gypsum sample is supersaturated with $\mathrm{Ca}^{2+}$ and $\mathrm{SO}_{4}{ }^{2-}$ ions. This situation promotes the nucleation of gypsum germs and their growth/precipitation. These precipitates are dissolved in the alkaline solution which is prepared for ion chromatography measurements. 

experimental electrical conductivities (in $\mathrm{mS} / \mathrm{cm}$ ) obtained for fired clay bricks and gypsum leachates
Table 4 Theoretical and

\begin{tabular}{lll}
\hline Sample & $\begin{array}{l}\text { Theoretical } \\
\text { conductivity }(\mathrm{mS} / \mathrm{cm})^{\circ}\end{array}$ & $\begin{array}{l}\text { Experimental } \\
\text { conductivity }(\mathrm{mS} / \mathrm{cm})\end{array}$ \\
\hline E_HB & 1.1 & 1.1 \\
E_FB & 0.9 & 0.7 \\
SW_HB & 2.8 & 2.5 \\
SW_FB & 2.3 & 2.3 \\
Gypsum & 7.33 & 2.9 \\
\hline
\end{tabular}

\begin{tabular}{lr}
\hline Sample & \multicolumn{1}{c}{$\beta$} \\
\hline E_HB & 0.4 \\
E_FB & 0.2 \\
SW_HB & 2.4 \\
SW_FB & 1.3 \\
Gypsum & 26.3 \\
\hline
\end{tabular}

Table 5 Supersaturation coefficients for leachates from single fired clay bricks and gypsum samples percentages of $0,1,2,3,4,5,10,15,20,25,50,75$ and $100 \%$ in Fig. 3.

For $1 \mathrm{wt} \%$ of gypsum, the electrical conductivity of the mixture reached $52 \%$ of the electrical conductivity of the individual gypsum sample. Moreover, the higher the mass fraction is, the higher the electrical conductivity is. These curves show that variations of the electrical conductivity with the addition of gypsum are getting close to a maximum electrical conductivity value that corresponds to the conductivity of gypsum alone. Furthermore, the shape of the curve changes for mixtures with $50 \mathrm{wt} \%$ of gypsum and more. Electrical conductivity quickly increases as soon as the experiment begins, then decreases slightly before increasing again progressively over time. This behaviour is similar to the behaviour of gypsum alone as noted in Fig. 2 .

Given that the increase of the gypsum mass fraction in mixtures generates an increase in electrical conductivity, measurement of the electrical conductivity could be an indicator to evaluate gypsum content of an unknown mixture. Actually, due to the maximum electrical conductivity value, it is possible to determine the mass percentage of gypsum which remains in the fired clay brick surface after separation.
Fig. 3 Electrical conductivities for fired clay bricks/gypsum mixtures as a function of time (prepared from waste collected in the Eastern waste processing site)

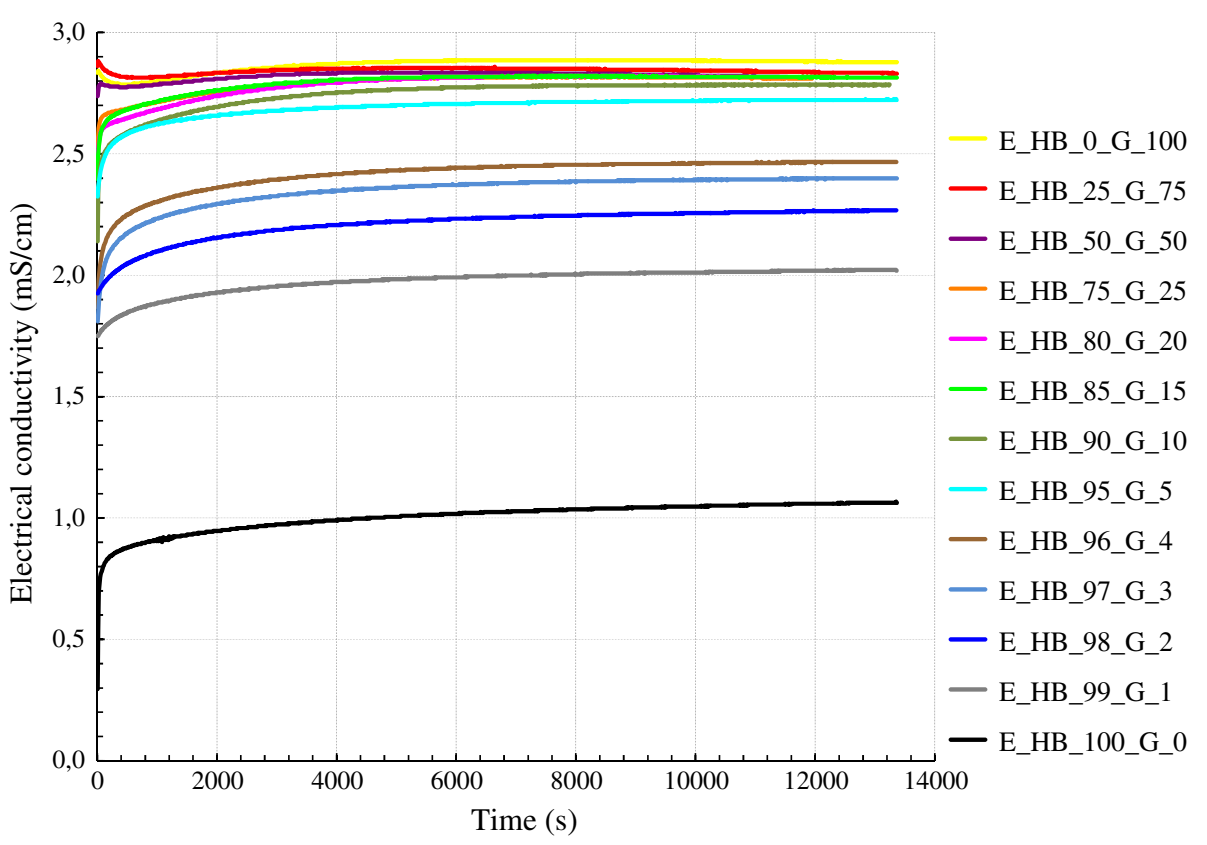


Figure 2 shows that the electrical conductivities of fired clay bricks depend on the nature and the geographical origin of these materials. Among all studied fired clay bricks, hollow clay bricks from the South West treatment plant have the biggest electrical conductivity in contact with water. Mixtures were also prepared from hollow clay bricks and gypsum composite samples collected in the waste processing sites in the South-West of France. In the same way, electrical conductivities of these samples were measured (Fig. 4).

For the samples collected in the South-Western waste processing site, it was noticed that the higher the fraction of gypsum is, the higher the electrical conductivity of the respective leachate is. Electrical conductivity of clay hollow bricks collected in the South-Western waste processing site is higher than that of clay hollow bricks collected in the East. Therefore, the electrical conductivity gap between the individual hollow brick sample and the individual gypsum sample is larger in the Eastern waste than in the SouthWestern one. Nevertheless, $1 \mathrm{wt} \%$ of gypsum in the mixture is still enough to increase significantly the electrical conductivity value of the leachate. In fact, although the gap between electrical conductivity values of a fired clay sample and a gypsum sample is different for waste collected in the East and the South-West of France, the mechanisms are comparable and still proportional to the conductivity scale between fired clay brick and gypsum samples. As a consequence, irrespective of the origin of the waste, the electrical conductivity can be correlated to the gypsum content which remains on the fired clay brick surface after separation.

Sulphate concentrations of the obtained leachates were determined by ion chromatography (Table 6).
Table 6 Sulphate concentrations (in $\mathrm{mg} / \mathrm{L}$ ) of leachates obtained from mixtures containing increasing content of gypsum

\begin{tabular}{lc}
\hline Sample & $\mathrm{SO}_{4}{ }^{2-}(\mathrm{mg} / \mathrm{L})$ \\
\hline E_HB_100_G_0 & 174 \\
E_HB_99_G_1 & 1290 \\
E_HB_98_G_2 & 1491 \\
E_HB_97_G_3 & 1500 \\
E_HB_96_G_4 & 1638 \\
E_HB_95_G_5 & 2007 \\
E_HB_90_G_10 & 2105 \\
E_HB_85_G_15 & 2196 \\
E_HB_80_G_20 & 2274 \\
E_HB_75_G_25 & 2335 \\
E_HB_50_G_50 & 2384 \\
E_HB_25_G_75 & 2421 \\
E_HB_0_G_100 & 2532 \\
\hline
\end{tabular}

Gypsum content of analysed mixtures influences sulphate concentrations of corresponding leachates. Actually, the higher the fraction by weight of gypsum in the mixture, the more the sulphate concentration of corresponding leachates increases. Furthermore, $1 \mathrm{wt} \%$ of gypsum in the mixture is sufficient to double the sulphate concentration of leachate.

The electrical conductivity as a function of sulphate concentrations of corresponding leachates was plotted for the same leaching time (Fig. 5).

The electrical conductivity increases linearly with the sulphate concentrations of corresponding leachates for low contents of gypsum in fired clay brick/gypsum mixtures.
Fig. 4 Electrical conductivities for fired clay bricks/gypsum mixtures as a function of time (prepared from waste collected in the South-Western waste processing site)

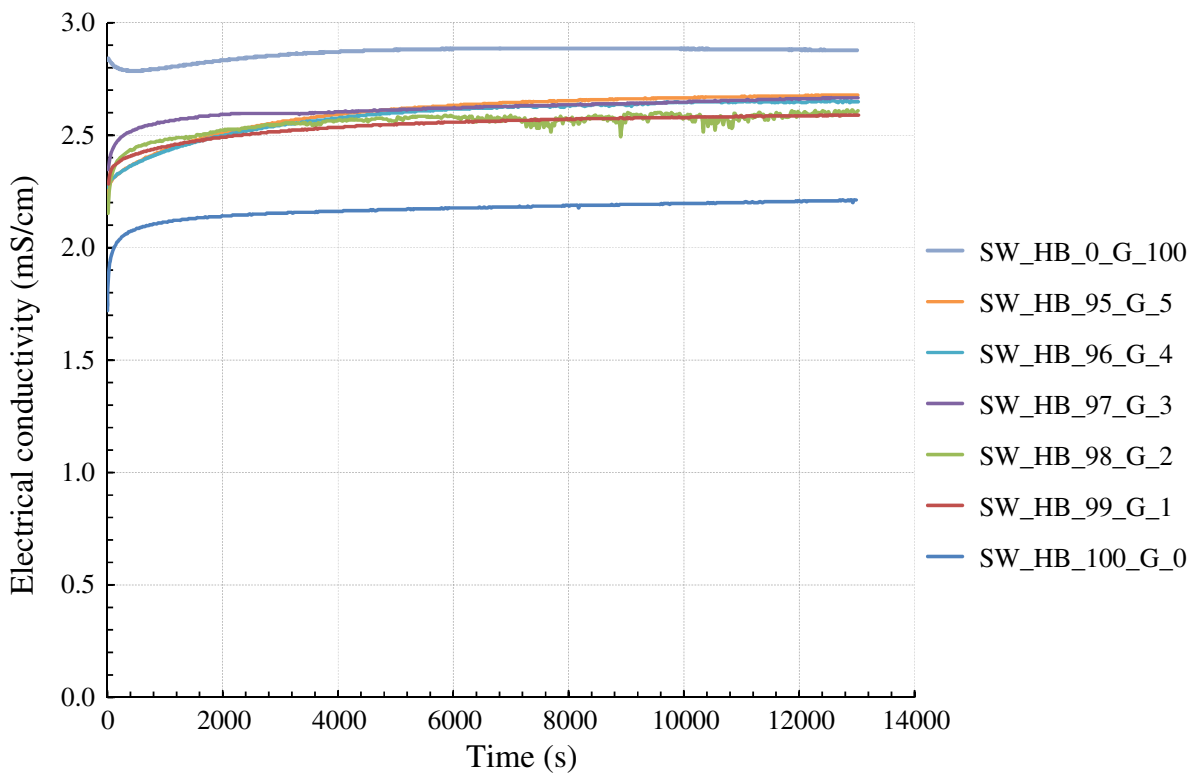




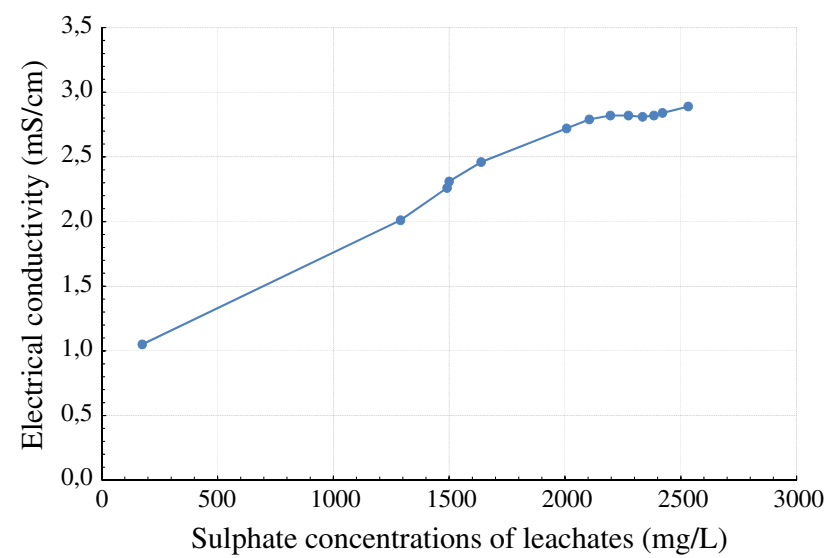

Fig. 5 Correlation between electrical conductivity and sulphate concentrations of corresponding leachates

From $5 \mathrm{wt} \%$ and greater of gypsum in the mixture, the sulphate concentration approaches a threshold corresponding to the water solubility of gypsum. In fact, making the assumption that all dissolved sulphates originate from gypsum $\left(\mathrm{CaSO}_{4}, 2 \mathrm{H}_{2} \mathrm{O}\right)$, and considering that the water solubility of gypsum is equal to $2.1 \mathrm{~g} \mathrm{~L}^{-1}\left(0.012 \mathrm{~mol} \mathrm{~L}^{-1}\right)$ at $25{ }^{\circ} \mathrm{C}$, it is noteworthy that corresponding leachates of mixtures containing more than $5 \mathrm{wt} \%$ of gypsum are supersaturated.

To conclude, the aim of this work was to find a simple test in order to check if the fired clay bricks are still polluted by gypsum after the separation process and to evaluate if the sulfate content is above the acceptable level of $2000 \mathrm{mg} / \mathrm{L}$. Electrical conductivity measurements can be proposed as a useful indicator: if the remaining gypsum is less than $5 \mathrm{wt} \%$, the sulfate level is acceptable. However, above $5 \mathrm{wt} \%$ of gypsum, the sulfate content is too high for re-use of clay bricks.

\section{Conclusion}

Analyses of leachates show that fired clay bricks are likely to leach sulphates $\left(\mathrm{SO}_{4}{ }^{2-}\right)$ when they are in contact with water. These sulphates originate from dissolution of sulphated compounds such as calcium sulphate, potassium sulphate and magnesium sulphate which were identified by XRD. Nevertheless, sulphate concentration depends on the type and the geographical origin of the studied waste. These differences may be mostly due to the manufacturing process of the clay bricks and to the origin of the raw materials. Sulphate concentration may also vary according to the brick's "history" (age of the building, environmental conditions in use).

Gypsum contents of prepared mixtures are correlated to the electrical conductivity of respective leachates.
Electrical conductivity characterizations and determination of sulphate concentrations of these leachates show that the higher the mass of gypsum of prepared mixtures increases, the more the electrical conductivity increases and the more the sulphate concentration of respective leachates increases.

As a consequence, electrical conductivity measurements as a function of time could be an efficient technique to evaluate if low gypsum content has remained or not on the surface of fired clay bricks after the separation process. However, the electrical conductivity maximum value differs from one geographical origin to another and from one type of fired clay bricks to another. Therefore, electrical conductivity measurements will be able to qualify the efficiency of the separation method only if the composite fired clay bricks and gypsum or mortar waste come from the same demolition site and are of the same type. It means that waste should be processed gradually and not as a mix of various types of fired clay bricks waste.

Acknowledgements Financial support for this project from the French Agency for the Environment and Energy Management (ADEME), as part of project RECYTEC (Recycling of fired clay based C\&DW) is gratefully acknowledged. The authors would like to thank also the French national association for research and technology (ANRT) and Prof. D.S. Smith (SPCTS) for his useful comments.

Open Access This article is distributed under the terms of the Creative Commons Attribution 4.0 International License (http://crea tivecommons.org/licenses/by/4.0/), which permits unrestricted use, distribution, and reproduction in any medium, provided you give appropriate credit to the original author(s) and the source, provide a link to the Creative Commons license, and indicate if changes were made.

\section{References}

1. Eurostat, environment and energy, Generation and treatment of waste, http://ec.europa.eu/eurostat/, 2010 (last accessed April 2016 of 2016)

2. Monier, V., Hestin, M., Travieux, M., Mimid, S., Domrose, L., Van Acoleyen, M., Hjerp, P., Mudgal, S.: Study on the management of construction and demolition waste in the EU. Contract 07.0307/2009/540863/SER/G2, Final report for the European Commission (DG Environment) (2011)

3. European Commission: Construction and Demolition Waste (C\&DW). (2014) http://ec.europa.eu/environment/waste/con struction_demolition.htm (last accessed on June 17 of 2016)

4. Kuryatnyk, T.: Insensibilisation à l'eau des mélanges à base de sulfate de calcium par ajout de calcium sulfo-alumineux, $\mathrm{PhD}$ Thesis, INSA Lyon (France) (2007)

5. Asakura, H.: Removing gypsum from construction and demolition waste $(C \& D W)$. In: Handbook of recycled concrete and demolition waste, vol. 19, pp. 479-499. (2013)

6. Agrela, F., Sanchez de Juan, M., Ayuso, J., Geraldes, V. L. , Jimenez, J. R.: Limiting properties in the characterization of mixed recycled aggregates for use in the manufacture of concrete. Constr. Build. Mater. 25, 3950-3955 (2011) 
7. Barbudo, A., Galvin, A.P., Agrela, F., Ayuso, J., Jimenez, J.R.: Correlation analysis between sulphate content and leaching of sulphates in recycled aggregates from construction and demolition wastes. Waste Manag 32, 1229-1235 (2012)

8. SETRA, Technical department for transport, roads and bridges. Acceptability of Alternative Materials in Road ConstructionEnvironmental assessment, www.centre-est.cerema.fr/IMG/pdf/ SETRA_2011-03_Valorisation_MA_Version-anglaise_cle12112 a-1.pdf (2011)

9. Silva, R.V., de Brito, J., Dhir, R.K.: Properties and composition of recycled aggregates from construction and demolition waste suitable for concrete production. Constr. Build. Mater. 65, 201-217 (2014)

10. Vegas, I., Ibanez, J.A., Lisbona, A., Saez de Cortazar, A., Frias, M.: Pre-normative research on the use of mixed recycled aggregates in unbound road sections. Constr. Build. Mater. 25, 2674-2682 (2011)
11. UNE-EN 13139: Aggregates for mortar (2002)

12. Butera, S., Christensen, T.H., Astrup, T.F.: Composition and leaching of construction and demolition waste: inorganic elements and organic compounds. J. Hazard. Mater. 276, 302-311 (2014)

13. Vegas, I., Broos, K., Nielsen, P., Lambertz, O., Lisbona, A.: Upgrading the quality of mixed recycled aggregates from construction and demolition waste by using near-infrared sorting technology. Constr. Build. Mater. 75, 121-128 (2015)

14. NF EN ISO 10304-1. Determination of dissolved anions by liquid chromatography of ions (2009)

15. Kornmann, M.: Matériaux de construction en terre cuiteFabrication et propriétés, Septima (2005)

16. Amathieu, L., Boistelle, R.: Crystallisation kinetics of gypsum from dense suspension of hemihydrate in water. J. Cryst. Growth 88, 183-192 (1988) 